12

\title{
Экспериментальные исследования таунсендовского разряда с многоострийным катодом на динамической платформе из магнитоуправляемых частиц Fe и Fe-Al
}

\author{
(C) И.А. Шорсткий, ${ }^{1}$ N. Yakovlev ${ }^{2}$ \\ ${ }^{1}$ Лаборатория передовых электрофизических технологий и новых материалов, \\ Кубанский государственный технологический университет, \\ 350072 Краснодар, Россия \\ ${ }^{2}$ Advanced Characterisation and Instrumentation (ACI) Department, \\ Institute of Materials Research and Engineering ( $\left.A^{*} \mathrm{STAR}\right)$, \\ 138634 Singapore \\ e-mail: i-shorstky@mail.ru
}

Поступило в Редакцию 9 января 2021 г.

В окончательной редакции 31 марта 2021 г.

Принято к публикации 4 апреля 2021 г.

\begin{abstract}
Представлены результаты экспериментальных исследований таунсендовского разряда в воздухе атмосферного давления с многоострийного катода на базе динамической платформы из магнитоуправляемых частиц $\mathrm{Fe}$ и $\mathrm{Fe}-\mathrm{Al}$. Приведен метод формирования магнитоуправляемой динамической платформы для поверхности катода. Получены вольт-амперные характеристики для различных конфигураций исполнения катода (с плоским электродом без магнитоуправляемых частиц, с многоострийным катодом с магнитоуправляемыми частицами $\mathrm{Fe}$ или $\mathrm{Fe}-\mathrm{Al}$ ), а также с наличием в катодной плоскости нагреваемой спирали. Использование многоострийного катода с динамической платформой из магнитоуправляемых частиц $\mathrm{Fe}$ и $\mathrm{Fe}-\mathrm{Al}$ позволило сохранить среднюю напряженность электрического поля в разрядном промежутке и увеличить ток искрового разряда.
\end{abstract}

Ключевые слова: таунсендовский разряд, многоострийный катод, динамическая платформа, магнитоуправляемая частица, вольт-амперная характеристика, ионный ток.

DOI: $10.21883 / J T F .2021 .08 .51105 .4-21$

\section{Введение}

Поверхность электродов в высоковольтных разрядных системах, работающих при атмосферном давлении, быстро разрушается под действием бомбардировки электронами и ионами остаточных газов [1]. Особое значение фактор подобного разрушения имеет для технологий обработки неравновесной низкотемпературной плазмой в металлургии, микроэлектронике, а также в химической и пищевой промышленности [2]. Последняя, в свою очередь, зарекомендовала себя как перспективное направление в подготовке пищевых продуктов к последующей переработке: обеззараживание продуктов [3], воздействие на анатомическую целостность растительных материалов (процесс электропорации) [4], реализация плазмохимических реакторов [5], подготовка семян к прорастанию [6] и другие.

Известно, что при работе с биологическими материалами необходимо учитывать их термолабильность [7], что требует контроля температурного фактора обработки, возникающего вследствие джоулева тепла от проходящего разряда. В связи с этим наиболее подходящим способом генерации неравновесной низкотемпературной плазмы с малыми значениями тока является формирование таунсендовского разряда (ТР) [8]. Основным преимуществом ТР является наличие достаточной дви- жущей силы процесса (напряженности поля) и малого по величине тока, что дает возможность проводить обработку пищевых продуктов без нагрева материала $[9,10]$. Для реализации ТР применительно к биологическим материалам необходимо использование специальных мер стабилизации разряда, таких, как оснащение катодной плоскости дополнительным термоэмиссионным источником электронов [11].

В отличие от тлеющего разряда атмосферного давления, в создании которого используется электродная система с коронирующими остриями и плоским анодом [12], для создания ТР наибольшее распространение получила классическая конфигурация электродов, где анод и катод выполнены в виде плоскости [13].

В динамике развития роста ионизации узким местом ТР является прикатодная область, отвечающая за эмиссию электронов с катода. В связи с этим в некоторых работах исследуется взаимосвязь параметров потока, распределения напряжения и тока ТР в комбинации с модификацией геометрии катода $[14,15]$.

Несмотря на многообразие технологий формирования многоострийных катодов [16-18], авторам данной работы не удалось обнаружить технологию формирования катодной поверхности с магнитодинамической платформой на основе магнитоуправляемых частиц. 
$a$
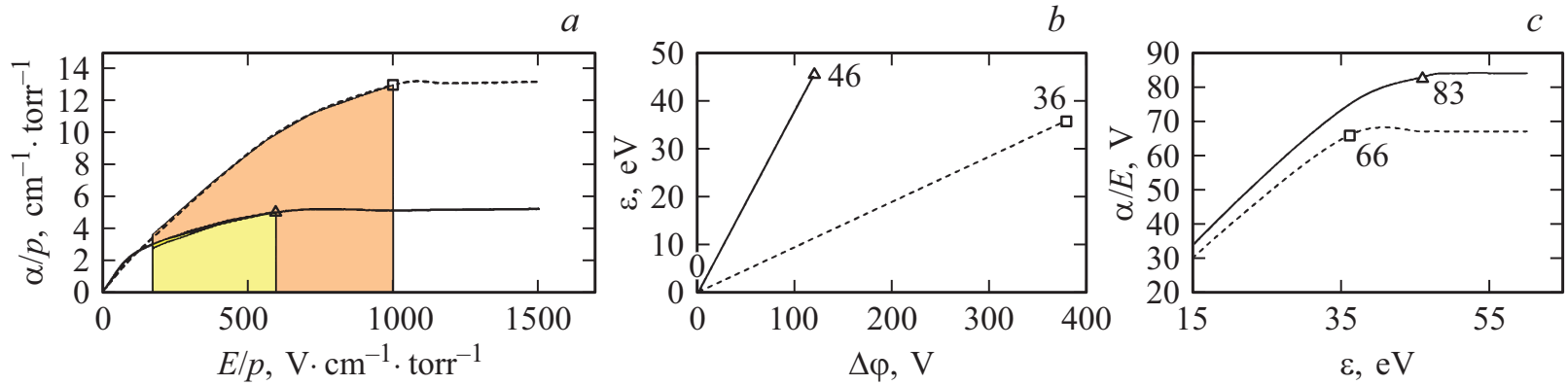

Рис. 1. Зависимость нормированного на давление значения модуля коэффициента Таунсенда $\alpha / p$ от приведенной напряженности поля $E / p(a)$, зависимость среднего значения энергии расходуемой быстрыми электронами на создание пары электрон-ион в газовой среде от разности потенциалов, которую проходит электрон в силовом электрическом поле до момента ионизации $(b)$, и зависимость разности потенциалов $(\alpha / E)^{-1}$, которую проходит электрон в поле с напряженностью $E$ в зависимости от средней энергии быстрых электронов и указанием постоянной Столетова в маркерных точках $(c)$. Непрерывная линия - воздух, штриховая линия - водород.

Настоящая работа направлена на стабилизацию ТР путем модификации поверхности плоского катода динамичными волокнистыми токопроводящими структурами из микросферических частиц $\mathrm{Fe}$ и частиц $\mathrm{Fe}$, покрытых оболочкой из токопроводящих наноразмерных частиц $\mathrm{Al}$, ориентированных по вектору магнитного поля диполя. Такая модификация создаст условия для сохранения средней напряженности электрического поля в разрядном промежутке и увеличения тока разряда.

Дополнительно рассматривается интеграция нити накаливания термоэлемента в структуру многоострийного катода для подтверждения гипотезы о довольно малой дрейфовой скорости электрона, которую он приобретает во внешнем электрическом поле между катодом и анодом, по сравнению с тепловой хаотической скоростью.

\section{1. Теоретическая часть}

Средняя энергия быстрого электрона в газовой среде расходуется на создание пары электрон-ион из молекулы газа как результата неупругого столкновения в межэлектродном пространстве [19]. Согласно феноменологической модели Таунсенда, ионизационная способность электронов определяется выражением [19]:

$$
\eta=\frac{\alpha}{E}=\left(\frac{p}{e}\right) A_{p} \exp \left(-\frac{B_{p}}{E / p}\right),
$$

где $\alpha$ - первый ионизационный коэффициент Таунсенда, $p$ - давление газа, $A_{p}$ и $B_{p}$ - эмпирические постоянные, зависящие от рода газа, $E-$ напряженность электрического поля.

Физический смысл значений $(\alpha / E)$ и $(E / p)$ из выражения (1) заключается в том, что разность потенциалов, которую проходит электрон на определенном участке, соответствует величине средней энергии, при которой совершается одиночный акт ионизации. Величина $(E / p)$ уменьшается с ростом давления газа в межэлектродном пространстве, и электрон претерпевает большое количество неупругих столкновений.

На рис. 1, $a$ представлен график роста коэффициента ионизации в координатах $(\alpha / p)$ и $(E / p)$ для первичного таунсендского ионизационного коэффициента согласно выражению (1) в газовой среде воздуха и водорода $\mathrm{H}_{2}$. Точки на рис. $1, a$, выделенные маркером, характеризуют насыщение первого ионизационного коэффициента Таунсенда согласно выражению (1). Известно, что для воздуха эта величина составляет $13 \mathrm{~cm}^{-1} \mathrm{Torr}^{-1}$ при $1000 \mathrm{~V}$, а для водорода $-5 \mathrm{~cm}^{-1}$ Torr $^{-1}$ при $600 \mathrm{~V}$ [20].

На рис. $1, b$ представлен график разгона электрона в поле с напряженностью $E$ до среднего значения энергии, необходимой для совершения акта ионизации молекулы газа. Точки, выделенные маркером, характеризуют разность потенциалов $\Delta \varphi$, которую преодолевает электрон в силовом электрическом поле для совершения акта ионизации за счет приобретенной средней энергии. Так, для водорода эта величина составляет $36 \mathrm{eV}$ при $E / p=140 \mathrm{~V} /(\mathrm{cm} \cdot T o r r)$, для воздуха $-46 \mathrm{eV}$ при величине $E / p=365 \mathrm{~V} /(\mathrm{cm} \cdot$ Torr) [20,21].

Для оценки величины насыщения актов ионизации со стороны средней энергии быстрых электронов в межэлектродном пространстве используют график в координатах $\alpha / E$ и $(\varepsilon)$, представленный на рис. $1, c$. Если растет средняя энергия электрона, то число актов ионизации в значении $(\alpha / E)$ достигает минимального значения, и энергия, теряемая на ионизацию, становится постоянной, принимая значение константы Столетова.

На рис. $1, c$ точки, выделенные маркером, характеризуют барьер разности потенциалов $(\alpha / E)$, который преодолевает электрон, обладая средней энергией акта ионизации в силовом электрическом поле напряженностью $E$. Графически количество актов ионизации на участке с разностью потенциалов $1000 \mathrm{~V}$ можно представить в виде шкалы, изображенной на рис. 2.

Так, электрон при нахождении в силовом электрическом поле на участке с разностью потенциалов $1000 \mathrm{~V}$ совершит порядка 15 актов ионизации в среде водорода 


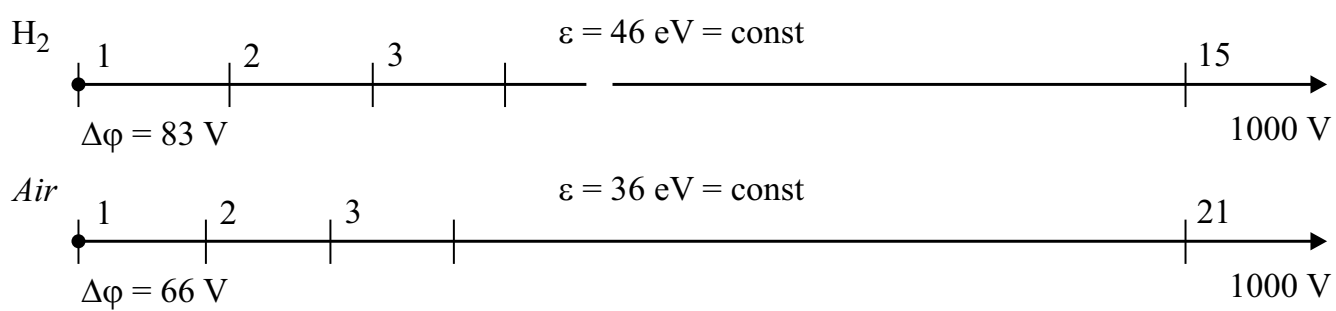

Рис. 2. Количество актов ионизации в газовой среде водорода и воздуха для классического плоскопараллельного катода.

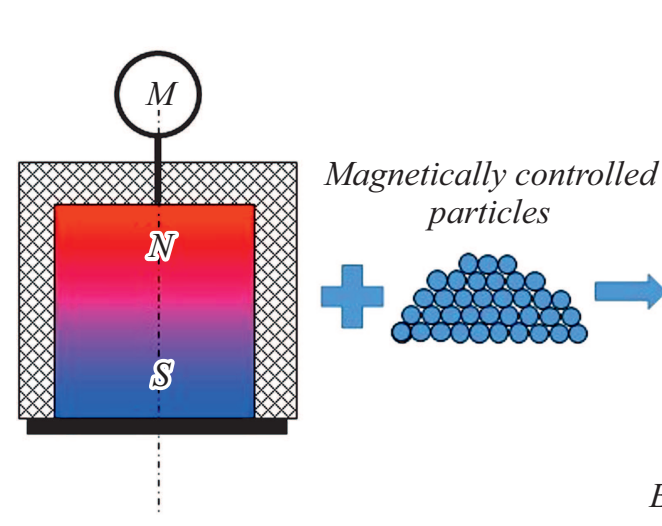

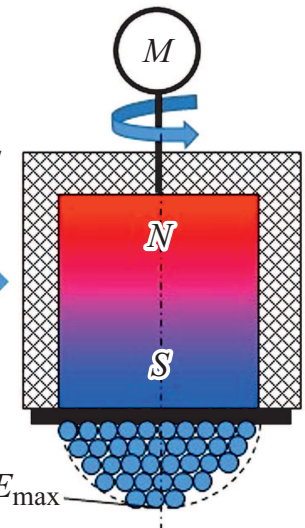

$b$

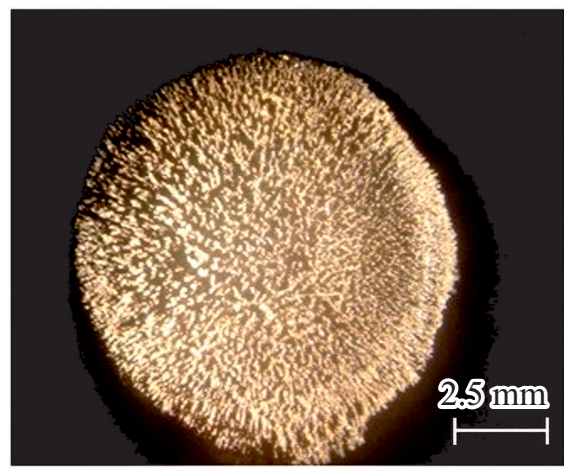

Рис. 3. Схема получения динамической платформы из магнитоуправляемых частиц (a) и изображение многоострийной поверхности катода, сформированной по результату инициализации массива частиц Fе вращающимся магнитным полем диполя $(b)$.

при условии сохранения им средней энергии $46 \mathrm{eV}$ и 21 акт ионизации при нахождении в газовой среде воздуха при условии сохранения им средней энергии $36 \mathrm{eV}$.

\section{2. Электродная конфигурация в однородном электрическом поле}

Снижение величины напряженности электрического поля в межэлектродном пространстве для совершения ТP возможно за счет изменения конфигурации поверхности катода [21]. В работе предлагается способ формирования многоострийного катода в виде динамической платформы на базе магнитоуправляемых частиц. Принцип формирования заключается в использовании вращательного магнитного поля цилиндрического постоянного магнита. Для этого на неподвижную токопроводящую подложку наносили требуемое количество магнитоуправляемых частиц для формирования плоскопараллельных и объемных поверхностей. Благодаря вращению постоянного магнита вокруг центральной оси диполя частицы под действием силовых линий магнитного поля выстраивались в многоострийную структуру с игольчатыми окончаниями как для плоских, так и для объемных поверхностей (рис. 3).

Для плоскопараллельных многоострийных структур поверхности катода особенность формируемой поверх- ности состоит в наличие острых окончаний, сформированных магнитоуправляемыми частицами $\mathrm{Fe}$ и удерживаемых постоянным магнитным полем диполя. Размер выступов вершин $h \geq d$, где $d-$ диаметр частиц.

Для многоострийных структур поверхности катода число остроконечных вершин определяется выражением

$$
E_{\max }=\sum_{i=1}^{n} E_{i} .
$$

Для объемных структур из магнитоуправляемых частиц, участвующих в конфигурации поверхностей катода, учитывается максимальная плотность магнитного поля, находящаяся в центре окружности цилиндрического диполя (рис. 4,a). Распределение внешнего эклектического поля в межэлектродном пространстве на вершине искусственной поверхности сфероида (катода) имеет максимальное значение по линии симметрии, проходящей через центры окружности цилиндра (рис. 4).

Для определения напряженности поля между катодом и анодом, независимо от вида приложенного напряжения, необходимо выполнить калибровку напряженности поля на поверхности катода. Напряженность поля на поверхности катода строится из горизонтальных линий в зоне однородного электрического поля $E_{0}$, как эквипотенциальные поверхности (рис. $4, b$ ), которые огибают рельеф сфероида. Силовые линии электрического поля между катодом и анодом параллельны оси ординат. 


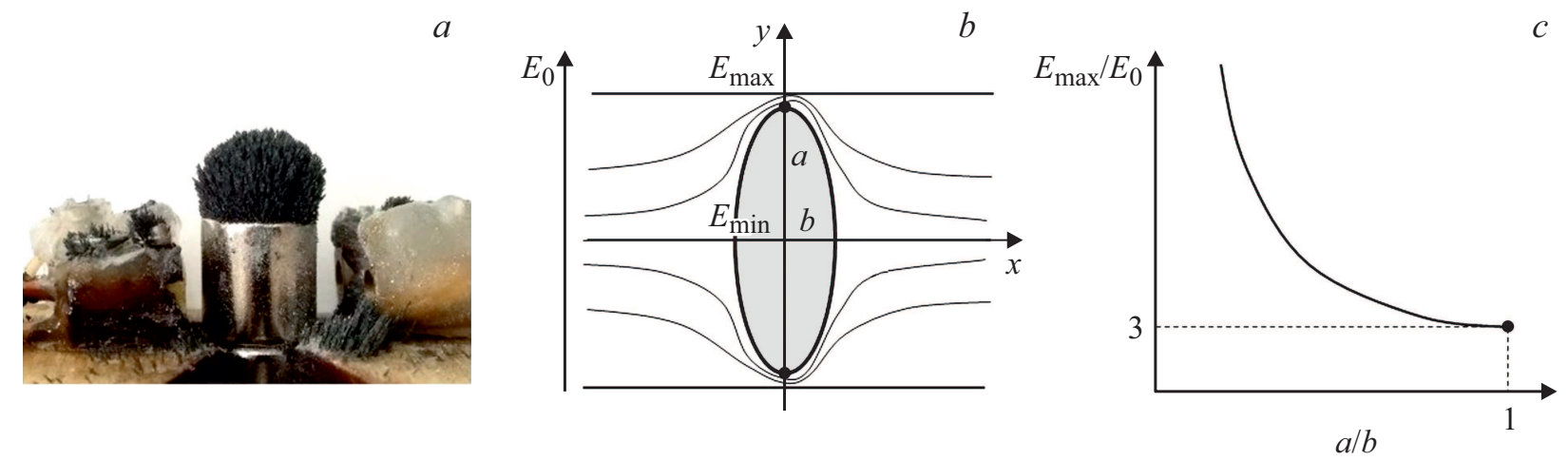

Рис. 4. Элипсообразная многоострийная поверхность катода $(a)$, эквипотенциальные линии напряженности электрического поля $(b)$ и величина максимальной напряженности поля на вершине в зависимости от геометрии эллипсоида $(c)$.

Центр эквипотенциального поля представлен пересечением осей $x$ и $y$. Для металлических сфероидов с хорошей электропроводностью поверхность напоминает вращающийся эллипс. Центр эллипса совмещен с началом координат по оси $x$ и по оси $y$. Параметры эллипсоида характеризуются геометрическими значениями полуосей $a$ и $b$.

Маркерная точка (рис. $4, b$ и $c$ ) характеризует максимальную плотность напряженности электрического поля, сосредоточенного на вершине эллипсоида при выполнении условия параллельности центральной оси эллипсоида вектору напряженности внешнего электрического пол $E_{0}$. На рис. $4, b$ маркерная точка характеризует поверхность как сферу при условии $a=b$. Напряженность электрического поля в маркерной точке превосходит напряженность внешнего электрического поля в 3 раза. Если рассматривать точки, принадлежащие поверхности эллипсоида при различных значениях полуосей $a$ и $b$, то напряженность в маркерных точках будет превосходить напряженность внешнего электрического поля $E_{0}$ во много раз.

\section{3. Термоэлектронная эмиссия}

При температуре металла 1000-2000 К электрон приобретает энергию от вибраций кристаллической решетки, достаточную для преодоления потенциального барьера. При высоких температурах термоэлектронная и автоэлектронная эмиссии будут действовать одновременно, что обеспечивает устойчивый газоразрядный процесс на этапе его формирования и на этапе его завершения при напряженности внешнего электрического поля на уровне $10^{3} \mathrm{~V} / \mathrm{cm}$. При наличии внешнего электрического поля $E_{0}$ ток автоэлектронной эмиссии начинает формироваться при напряженности внешнего электрического поля порядка $10^{7}-10^{8} \mathrm{~V} / \mathrm{cm}$. Электрическое поле понижает барьер потенциальной кривой электронного состояния на поверхности некоторого метала до уровня, при котором проявляется туннельный эффект (рис. 5).

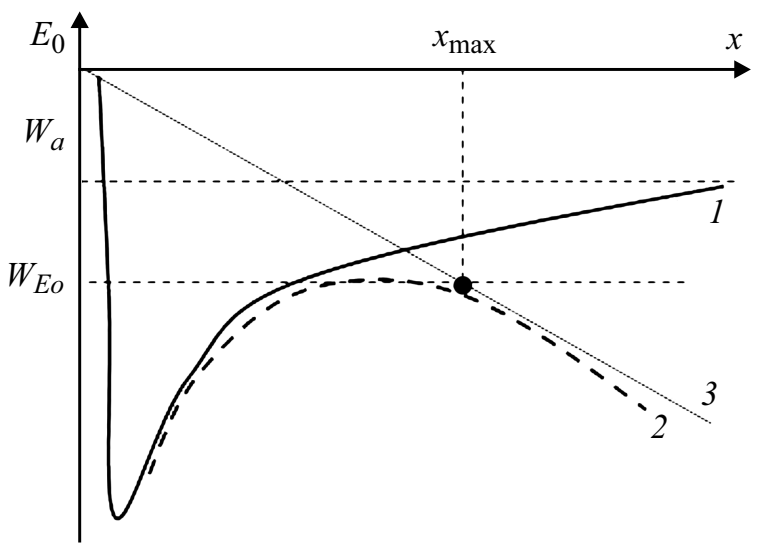

Рис. 5. Потенциальная кривая электронного состояния некоторого метала: 1 - без внешнего электрического поля; 2 - при наличии внешнего ускоряющего поля $E_{0} ; 3-$ линейная зависимость потенциальной энергии электрона во внешнем электрическом поле.

Ток насыщения как эмиссия электронов с поверхности катода при наличии внешнего электрического поля определяется выражением [21]

$$
J_{E_{0}}=A T^{2} \exp \left[-\frac{e}{R T}\left(W_{a}-\sqrt{\frac{e E_{0}}{4 \pi \varepsilon_{0}}}\right)\right]
$$

где $A-$ термоэлектрическая постоянная, $R-$ универсальная газовая постоянная, $W_{a}-$ работа выхода электрона из потенциальной кривой определенного металла $(2.98-4.43 \mathrm{eV}$ для алюминия и $3.91-4.6 \mathrm{eV}$ для железа), $\sqrt{\frac{e E_{0}}{4 \pi \varepsilon_{0}}}-$ потенциальная энергия электрона, приобретенная от внешнего электрического поля $E_{0}$, $e$ - заряд электрона.

При малых значениях напряженности электрического поля на уровне $10^{3} \mathrm{~V} / \mathrm{cm}$ используется уравнение Ричардсона-Дешмана:

$$
J_{s}=A T^{2} \exp \left[-\frac{1}{R T}\left(W_{a}\right)\right] .
$$




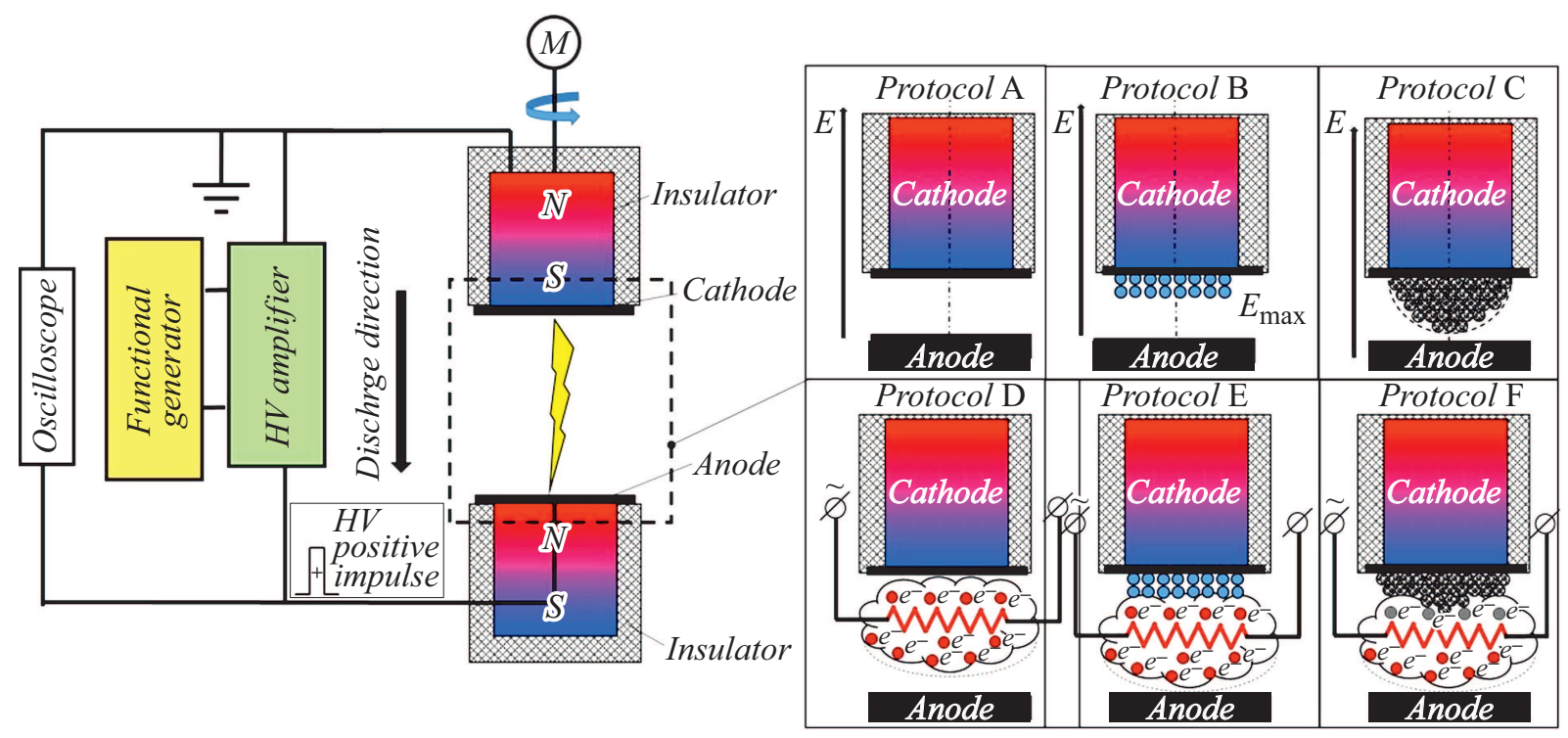

Рис. 6. Схема экспериментальной установки и опыты модификаций поверхности катода.

Выражение (3) характеризует плотность тока насыщения для эмиссии электронов из металла, разогретого до температуры, величина которой определяется величиной тока проходящего по нити накала.

\section{4. Методика измерений и аппаратура. Схема экспериментальной установки}

Схема экспериментальной установки представлена на рис. 6. В качестве источника положительных прямоугольных импульсов использовали систему, состоящую из функционального генератора Agilent 33220A (Agilent Technologies, USA) и высоковольтного усилителя Matsusada 20-B-20 (Matsusada Precision Inc, Japan). Максимальное напряжение на выходе усилителя составляло $20 \mathrm{kV}$. Контроль характеристик формы, амплитуды и длительности импульсной компоненты тока и напряжения разряда проводили с использованием четырехлучевого осциллографа Tektronix TDS 220. Подавался прямоугольный положительный импульс длительностью $50 \mu \mathrm{s}$. Величина активного сопротивления нити накала (источника термоэлектронной эмиссии) соответствовала $2 \Omega$, а величина приложенного напряжения - 0.9-1.1 V.

Для модификации катода были использованы магнитоуправляемые микрочастицы Fе размером $60 \mu \mathrm{m}$ (аббревиатура FM) и микрочастицы Fe, покрытые наноразмерными частицами $\mathrm{Al}$ порядка $100 \mathrm{~nm}$ (аббревиатура FAM) в соответствии с технологией [22]. В качестве подложки для катода использовали плоскую металлическую пластину, жестко закрепленную на корпус изолятора, внутри которого расположен постоянный магнит в виде цилиндра с диаметром поперечного сечения $10 \mathrm{~mm}$. Для конструктивного исполнения поверхности катода было рассмотрено 6 опытов (рис. 6).

- опыт А. Плоский классический катод без магнитоуправляемых частиц, расстояние между электродами $9.0 \mathrm{~mm}$;

- опыт В. Многоострийный катод из магнитоуправляемых частиц FM, выполненных в виде тонкого слоя толщиной $1 \mathrm{~mm}$, расстояние между плоским анодом и вершинами многоострийного катода $9.0 \mathrm{~mm}$;

- опыт С. Многоострийный катод из магнитоуправляемых частиц FAM, выполненных в виде сфероида, расстояние между плоским анодом и вершиной сфероида $9.0 \mathrm{~mm}$;

- опыт D. Плоский катод без магнитоуправляемых частиц и источником термоэлектронной эмиссии в виде нити накала, расстояние между плоским анодом и нитью накала $9.0 \mathrm{~mm}$;

- опыт Е. Катод из магнитоуправляемых частиц FM, выполненных в виде массива частиц, интегрированных в области нити накала, расстояние между плоским анодом и вершиной массива частиц $9.0 \mathrm{~mm}$;

- опыт F. Катод из магнитоуправляемых частиц FAM, выполненных в виде массива частиц, интегрированных в области нити накала, расстояние между плоским анодом и вершиной массива частиц $9.0 \mathrm{~mm}$.

Формирование конфигурации динамической платформы катода по опытам В, С происходило до образования плоской и объемной поверхности в соответствии с методом, описанным ранее. Для всех опытов использовали рабочий газ воздух при атмосферном давлении.

\section{5. Результаты измерений}

Быстрые электроны, стартующие с поверхности катода, ускоряются в прикатодном слое внешним электри- 

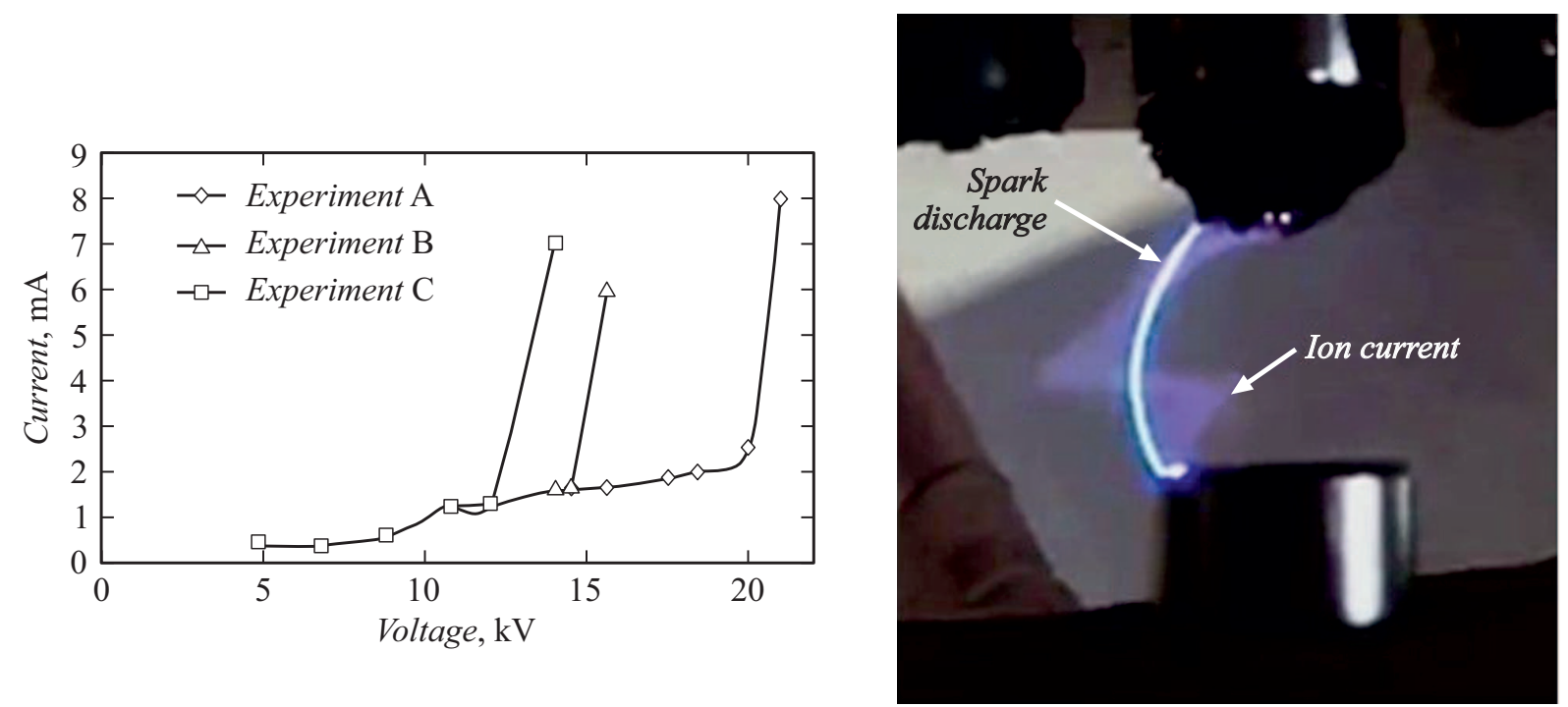

Рис. 7. Семейство ВАХ для опытов А-C при межэлектродном зазоре $9 \mathrm{~mm}$ и фотография разряда в опыте С при напряжении на электродах $14.6 \mathrm{kV}$.

ческим полем. Поле в разрядном промежутке определяется формой электродов, а также разностью потенциалов между ними. При рассмотрении электродной конфигурации по опытам А, В, С были получены данные, представленные на рис. 7. Полученное семейство BAX демонстрирует характерную зависимость для ТР при малых значениях силы тока при межэлектродном зазоре $9 \mathrm{~mm}$.

Фотография туансендского разряда в конфигурации электродов „многоострийный катод-плоский анод“ в соответствии с опытом $\mathrm{C}$ и его переход в искровую стадию представлена на рис. 7 справа. Искровой разряд формируется в межэлектродном промежутке, равном $9.0 \mathrm{~mm}$ при подаче на анод импульса напряжения положительной полярности. Вокруг искрового разряда формируется ток обратной полярности, визуализированный в виде объемного плазменного тела спиралеобразной формы голубого свечения.

Для визуального отображения данного эффекта лабораторная установка снабжена электродами, выполненными из неодимовых постоянных магнитных диполей цилиндрической формы. Согласно правилу поведения заряженных частиц, в продольных электрических и магнитных полях лабораторной установки при ориентации полюсов постоянных магнитов (электродов) в конфигурации $\mathrm{S}-\mathrm{N}$ заряженные частицы движутся по окружности и создают круговой ток. В зависимости от знака заряда движение будет осуществляться по часовой стрелке для отрицательных зарядов и против часовой стрелки для положительных. При неоднородном магнитном поле в межэлектродном пространстве движение заряженных частиц связано с ларморовским радиусом [23].

При сравнении ВАХ для опытов А, В, С (рис. 7) наблюдается снижение величины напряжения пробоя газовой среды межэлектродного пространства между анодом и катодом в лабораторной установке от величины $20.5 \mathrm{kV}$ для опыта А до величины $16.2 \mathrm{kV}$ для опыта В и величины $14.6 \mathrm{kV}$ для опыта C соответственно. Следует заметить, что величина тока для опытов А, B, C сохраняется на уровне 6-8 $\mathrm{mA}$. Снижение величины напряжения пробоя связано с изменением геометрии поверхности катода, в том числе с учетом линий эквипотенциальных поверхностей для опыта C (рис. 4).

Изменение напряжения пробоя по опыту В происходит благодаря множеству остроконечных вершин, равномерно распределенных по площади плоского многоострийного катода. Для опыта С снижение величины напряжения пробоя связано с формированием эллипсоидной поверхности из магнитоуправляемых частиц $\mathrm{Fe}-\mathrm{Al}$. Формирование вершины эллипса по линии симметрии магнитного диполя обеспечивает максимальную напряженность электрического поля, которая превосходит напряженность внешнего электрического поля многоострийного катода, сформированного по опыту В, на $1.6 \mathrm{kV}$ (рис. 7). В связи с тем что электропроводность динамического слоя магнитоуправляемых частиц $\mathrm{Fe}$, покрытых наноразмерными частицами $\mathrm{Al}$, находится в пределах $10^{3} \Omega$ вершина эллипсоида не может обеспечить большое снижение величины напряжения пробоя.

Осциллограммы напряжения на электродах лабораторной установки и тока разряда в межэлектродном пространстве при атмосферном давлении воздушной среды показаны на рис. 8.

На осциллограммах тока для опытов А и В отчетливо заметно запаздывание возрастания электронного тока от момента подачи напряжения на 40 и $80 \mu \mathrm{s}$ соответственно. Далее через 40-80 $\mu$ s ток достигает значения 6-8 mА в образе яркой нитевидной линии (рис. 7). По времени начало роста ионного тока соответствует появлению голубого свечения (рис. 7), а переход в от- 


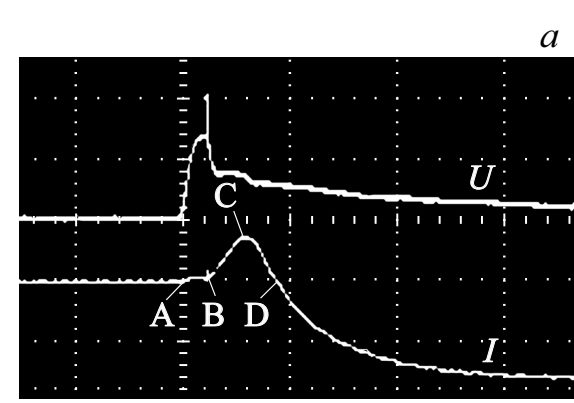

Scale: $10 \mathrm{kV}$ per cell, $10 \mathrm{~mA}$ per cell, $200 \mu$ s per cell

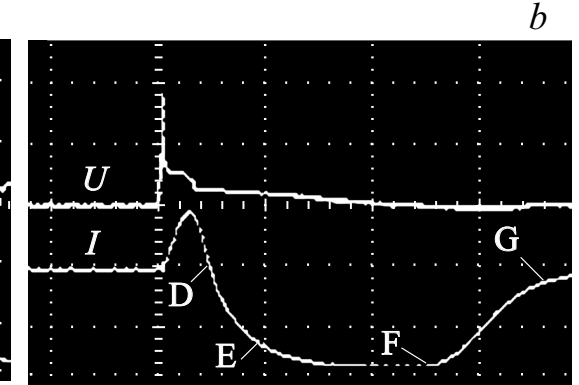

Scale: $10 \mathrm{kV}$ per cell, $10 \mathrm{~mA}$ per cell, Scale: $10 \mathrm{kV}$ per cell, $10 \mathrm{~mA}$ per cell, $400 \mu \mathrm{s}$ per cell $200 \mu \mathrm{s}$ per cell

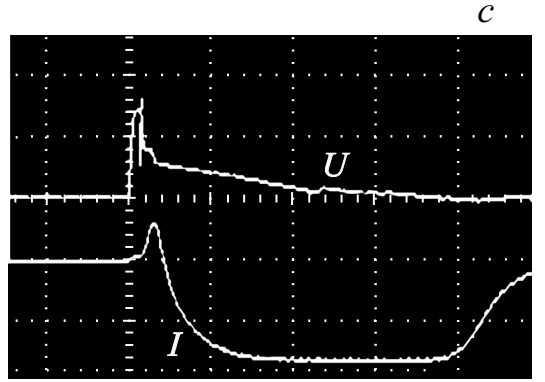

Рис. 8. Осциллограммы тока и напряжения опытов А $(a)$, В $(b)$ и С $(c)$. Рабочий газ - воздух.

рицательные значения величины тока - формированию объемного спиралеобразного плазменного тела, состоящего из положительных ионных компонентов. Длительность электронного тока (очевидно, эта стадия соответствует генерации процессов вторичной ионизации) существенно зависит от прикладываемого напряжения. Так, при $U=20.5 \mathrm{kV}$ длительность составляет $120 \mu \mathrm{s}$ для опыта А, при $U=16.2 \mathrm{kV}$ длительность составляет $80 \mu \mathrm{s}$ для опыта В. Это связано с величиной ионного тока, который направлен от анода к катоду, в результате чего ионный ток стремится противостоять электронному току, который направлен от катода к аноду. Результатом такого взаимодействия является сокращение времени существования тока искрового разряда.

Для понимания физического процесса и эволюции искрового разряда, наблюдаемого в авторской экспериментальной установке, на кривых тока разряда для опытов А и С выделены маркерные точки.

Кривая ABCD представляет собой кривую тока искрового разряда (рис. 8,a). При увеличении амплитуды напряжения в электродном промежутке диффузионный разряд (участок $\mathrm{AB}$ ) переходит в исковой разряд $\mathrm{BC}$, где наблюдается резкое увеличение плотности тока. Искровой разряд формируется в межэлектродном промежутке, равном $9.0 \mathrm{~mm}$, при подаче на анод импульса напряжения положительной полярности. Основными носителями искрового разряда, наблюдаемого в лабораторной установке на участке $\mathrm{ABCD}$, являются вторичные электроны, вырванные из катода. От катода к аноду вдоль канала проводимости движутся вторичные электроны, обладающие большой энергией. На рис. 7 искровой разряд представлен в виде нитевидной плазмы яркобелого цвета, возникающей при замыкании тока искрового разряда на анод лабораторной установки. Время жизни нитевидной плазмы искрового разряда характеризуется участком BCD. Точка C характеризует искровой ток с максимальной плотностью заряженных частиц (электронов). Точка D характеризуется, как завершение тока искрового разряда для электронных частиц, замыкающихся на аноде, при сохранении напряжения на электродах лабораторной установки на уровне $30 \%$ от напряжения искрового разряда в максимальной точке $\left(U_{\max }=18.0 \mathrm{kV}\right)$, что составляет $5.4 \mathrm{kV}$ для точки $\mathrm{D}$.

На участке DE (рис. 8,c) формируется ток обратной полярности, визуализированный в виде объемного плазменного тела спиралеобразной формы голубого свечения (рис. 7). На участке DE кривой тока наблюдается малый ларморовский радиус спиралеобразного плазменного тела голубого свечения, что связано с движения заряженных частиц (ионов) вблизи полюса диполя. На участке EF радиус ларморовской окружности увеличивается, что связано с низкой плотностью магнитных линий в данной области электродного пространства. Участок FG аналогичен участку DF при условии, что напряжение на электродах достигает нулевого значения в точке $\mathrm{G}$, где ионный ток замыкается на катод.

Возникновение ионного тока в виде объемного плазменного тела спиралеобразной формы голубого свечения авторы объясняют следующим образом. Рассмотрим особенность физического процесса, происходящего в маркерной точке $\mathrm{CD}$, где наблюдается завершение эволюции тока искрового разряда и начало формирования ионного тока. Механизм образования ионного тока связан с эффектом прилипания электронов, поступающих в катодную цепь лабораторной установки от внешнего источника (высоковольтного усилителя сигналов Matsusada 20-B-20) к наноразмерным частицам Al, которые расположены на поверхности микроразмерных частиц Fe, удерживаемых на поверхности катода с помощью постоянного магнита. Эффект прилипания позволяет дрейфовать пылевой частице Al с зарядом электрона в сторону анода вдоль силовых линий напряженности внешнего электрического поля $E_{0}$ (рис. 9). Скорость пылевых частиц Al с зарядом электрона много меньше скорости вторичных электронов, стартующих с поверхности многоострийного катода. Когда пылевая частица $(\mathrm{Al}+\mathrm{e})$ достигнет поверхности анода, электрон уходит в анод электрической цепи лабораторной установки, а наноразмерная частица получает кинетическую энергию по результату неупругого столкновения с вторичными электронами, двигающимися в силовом электрическом поле с напряженностью $E_{0}$, стартовавшими с катода. 

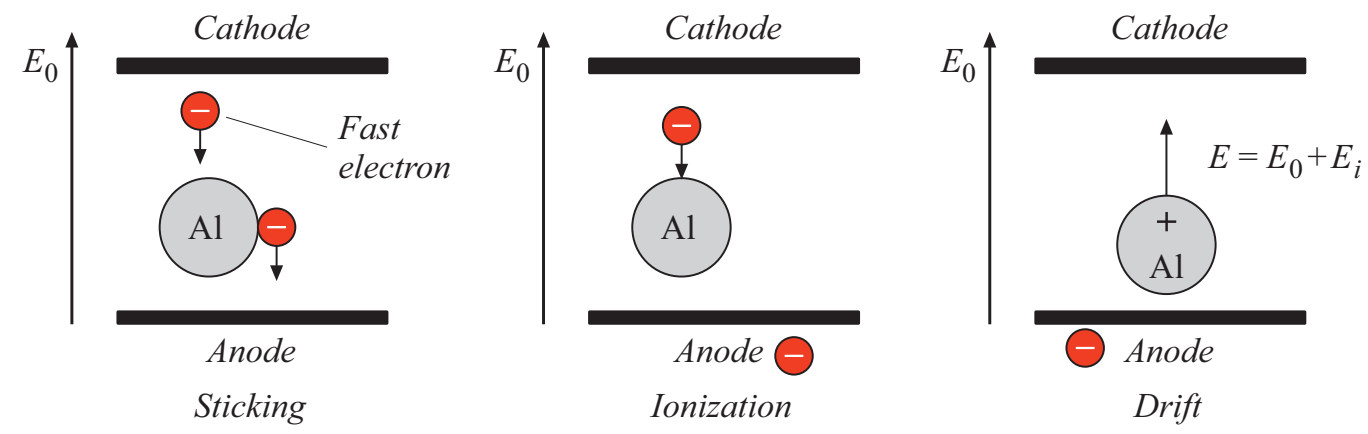

Рис. 9. Схема электрического поля в промежутке при ионизации частиц $\mathrm{Al}$.
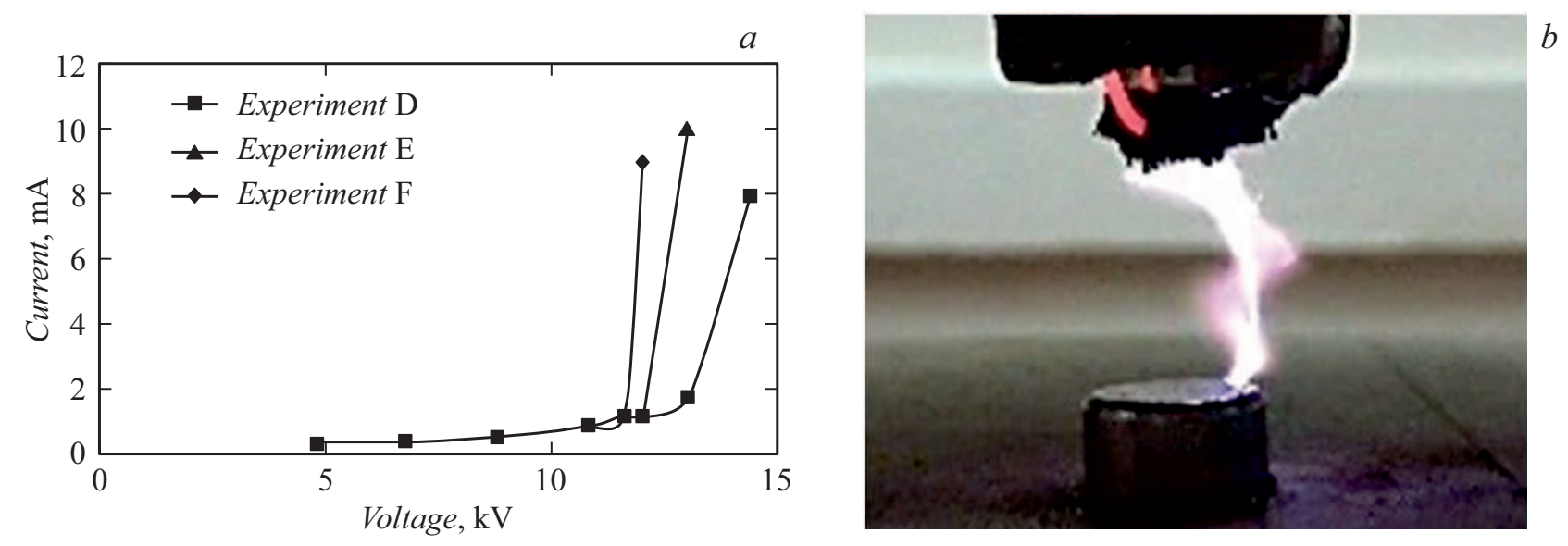

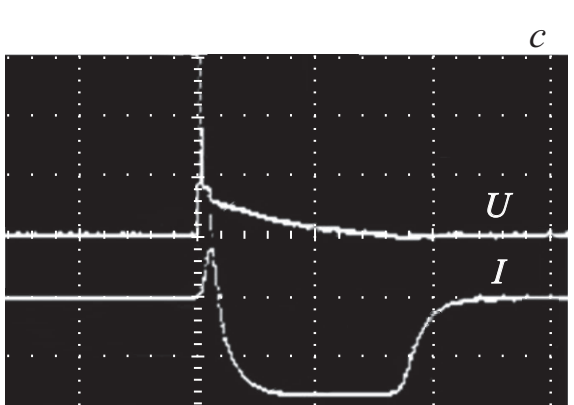

Scale: $10 \mathrm{kV}$ per cell, $1 \mathrm{~s}$ per cell

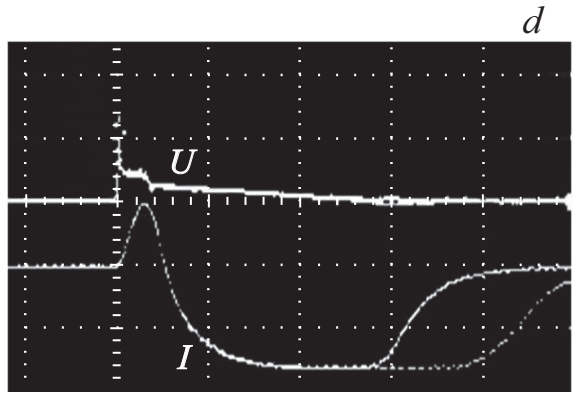

Scale: $10 \mathrm{kV}$ per cell, $400 \mu$ s per cell

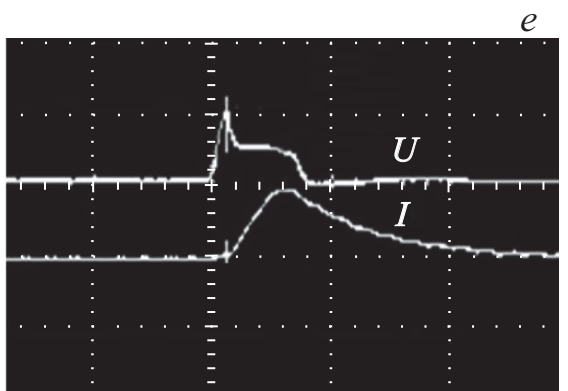

Scale: $10 \mathrm{kV}$ per cell, $200 \mu$ s per cell

Pис. 10. Семейство BAX для опытов $\mathrm{D}-\mathrm{F}$ при межэлектродном зазоре $9 \mathrm{~mm}(a)$, фотография разряда в опыте Е при напряжении $13.6 \mathrm{kV}(b)$ и осциллограммы тока и напряжения опытов $\mathrm{D}(c), \mathrm{E}(d)$ и $\mathrm{F}(e)$. Рабочий газ — воздух.

Результатом этого столкновения является ионизация частиц Al, которые становятся положительными ионами. На участке DE (рис. 8) наблюдается рост ионного тока до значения насыщения на участке $\mathrm{EF}$, что говорит о дрейфе пылевых частиц $(\mathrm{Al}+\mathrm{e})$ в анодную зону в виде порции частиц. Размер порции зависит от времени взаимодействия кинетических вторичных электронов с частицами $\mathrm{Al}$ на участке $\mathrm{BCD}$, составляющем $120 \mu \mathrm{s}$. Слабо ионизированный канал, состоящий из положительных ионов, зарождается в плоскости анода и разрастается до катода. Такой стример характеризуется, как катод-направленный.

На рис. 9 изображено результирующее электрическое поле, построенное за счет пространственного заряда положительных ионов, где $E_{0}$ - внешнее электрическое поле, а $E_{i}$ - поле объемного заряда положительных ионов пылевых наноразмерных частиц Al.

В соответствии с теоретическими материалами, представленными в разд. 1, сравнение количества актов ионизации для опытов А и В показало, что наличие многоострийных вершин при одинаковых условиях межэлектродного расстояния способствует росту количества актов ионизации в межэлектродном пространстве (см. таблицу).

Экспериментальные данные BAX для опытов D, E, F с наличием термоэлектронной эмиссии представлены на рис. $10, a$. 
Количественная оценка актов ионизации для опытов А и В

\begin{tabular}{c|c|c|c|c}
\hline Опыт & $\begin{array}{c}\Delta \varphi, \\
\mathrm{eV}\end{array}$ & $\begin{array}{c}\alpha / E, \\
\mathrm{~V}^{-1}\end{array}$ & $\begin{array}{c}E, \\
\mathrm{keV}\end{array}$ & $\begin{array}{c}\text { Количество актов ионизации } \\
\text { в межэлектродном пространстве }\end{array}$ \\
\hline $\mathrm{A}$ & 36 & 66 & 20.5 & 310 \\
$\mathrm{~B}$ & 36 & 66 & 16.0 & 242
\end{tabular}

Примеч ание. Межэлектродное расстояние $-9 \mathrm{~mm}$.

При сравнении BAX для опытов D, E, F наблюдается снижение величины напряжения пробоя газовой среды межэлектродного пространства между анодом и катодом в лабораторной установке от величины $14.4 \mathrm{kV}$ для опыта $\mathrm{E}$ до величины $13.6 \mathrm{kV}$ для опыта $\mathrm{F}$ и величины $12.2 \mathrm{kV}$ для опыта D при межэлектродном расстоянии $9 \mathrm{~mm}$.

Следует заметить, что величина тока для опытов $\mathrm{E}-\mathrm{F}$ меняется в сторону увеличения на уровне 1-2 $\mathrm{mA}$ по сравнению с классическим плоскопараллельным катодом совместно с нитью накала, сформированного согласно опыту D. Источниками роста электронного тока являются суммарный ток, состоящий из тока первичных электронов со стороны внешнего источника лабораторной установки, а также из тока вторичных электронов и дополнительного тока электронов, вызванных термоэлектронной эмиссией с работой выхода электронов для частиц $\mathrm{Fe}$, равной $3.91-4.6 \mathrm{eV}$, и для частиц $\mathrm{Al}$, равной $2.98-4.43 \mathrm{eV}$, накопленных на многоострийной динамической платформе.

Для опыта Е в виде многоострийного катода из магнитоуправляемых частиц, выполненных в виде массива частиц $\mathrm{Fe}$, интегрированных в область нити накала, ток пробоя увеличился на $2 \mathrm{~mA}$ по сравнению с опытом D. Это связано с низким удельным электрическим сопротивлением частиц железа, механически связанных между собой под действием вектора напряженности магнитного поля.

Для многоострийного катода по опыту F, выполненного в виде массива частиц $\mathrm{Fe}$ и $\mathrm{Al}$, интегрированных в область нити накала, ток пробоя увеличился на $1 \mathrm{~mA}$ по сравнению с опытом D. Это связано с высоким удельным электрическим сопротивлением наночастиц алюминия, плакированных на поверхности частиц железа, которые характеризуют электрическую цепь катод-анод лабораторной установки. Характерной особенностью опыта $\mathrm{F}$ является отсутствие ионного тока (рис. 10,e).

Снижение величины напряжения пробоя от 2.2 до $0.8 \mathrm{kV}$ (рис. 10) связано с наличием многоострийной поверхностью катода для опытов Е и F. Следует отметить, что снижение напряжения пробоя в опыте $\mathrm{F}$ связано с низкой электропроводностью наночастиц алюминия, что создает дополнительное падение напряжения в самом динамическом слое.

Примеры осциллограмм напряжения на электродах лабораторной установки и тока в межэлектродном пространстве показаны на рис. $10, c, d$. В отличие от опытов А и В на осциллограммах тока для опытов D и Е отсутствует запаздывание возрастания тока разряда от момента подачи напряжения. По времени начало роста тока соответствует возрастанию напряжения и появлению голубого свечения (рис. 8,b), а переход в отрицательные значения величины тока - формированию объемного плазменного тела, состоящего из ионных компонентов. Длительность электронного тока для опытов D и Е одинакова и соответствует величине $200 \mu \mathrm{s}$. Осциллограмма тока для опыта F характеризуется отсутствием отрицательных значений тока (ионного), а также обладает большей длительностью.

\section{Заключение}

Получены данные ТР для модифицированной катодной плоскости на базе динамической платформы из магнитоуправляемых микрочастиц $\mathrm{Fe}$ и $\mathrm{Fe}-\mathrm{Al}$. Установлено, что для сохранения средней энергии электронов при совершении актов ионизации в газовой среде необходимо использовать динамическую платформу в качестве многоострийного катода из магнитоуправляемых частиц $\mathrm{Fe}(\mathrm{FM})$, обладающих низкой электропроводностью на уровне $10^{-3}-10^{-4} \Omega$. Наличие токопроводящей оболочки алюминия на магнитоуправляемых частицах динамической платформы (FAM) приводит к росту величины ионного тока, что является негативным фактором при обработке биологических материалов, относящихся к термолабильным материалам. Комбинация динамической платформы с магнитоуправляемыми частицами FM и FAM с источником термоэлектронной эмиссии снижает величину напряженности электрического поля, необходимую для совершения ТР.

\section{Благодарности}

Работа выполнена в рамках гранта президента РФ для государственной поддержки молодых российских ученых МК-2188.2021.4.

\section{Конфликт интересов}

Авторы заявляют, что у них нет конфликта интересов.

\section{Список литературы}

[1] Г.Г. Соминский, Е.П. Тарадаев, Т.А. Тумарева, М.Е. Гиваргизов, А.Н. Степанова. ЖТФ, 86 (11), 108 (2016).

[2] C. Hertwig, N. Meneses, A. Mathys. Trends in Food Science \& Technology, 77, 131 (2018). DOI: /10.1016/j.tifs.2018.05.011

[3] B.G. Dasan, I.H. Boyaci. Food and Bioprocess Technology, 11, 334 (2018). DOI: 10.1007/s11947-017-2014-0

[4] И.А. Шорсткий. Применение обработки импульсным электрическим полем при подготовке к сушке (Издат. дом Юг, Краснодар, 2020) 
[5] C. Cheng, L. Peng, X. Lei, Z. Li-Ye, Z. Ru-Juan, Z. Wen-Rui. Chinese Physics, 15 (7), 2006. DOI: $10.1088 / 1009-1963 / 15 / 7 / 028$

[6] Б.Б. Балданов, Ц.В. Ранжуров, М.Н. Сордонова, Л.В. Будажапов. Успехи прикладной физики, 7 (3), 260 (2016).

[7] В.М. Арапов, М.В. Арапов, М.В. Мамонтов. Вестник Гомельского гос. тех. ун-та им. П.О. Сухого, 3 (26), 2006.

[8] С.3. Сахапов. Параметры плазмы сферически стратифицированного газового разряда: дис. - Институт теплофизики им. СС Кутателадзе СО РАН, 2008.

[9] I. Shorstkii, D. Khudyakov, M.S. Mirshekarloo. Innovative Food Science \& Emerging Technologies, 60, 102309 (2020). DOI: $10.1016 /$ j.ifset.2020.102309

[10] Пат. 2727915 РФ. Способ подготовки растительного материала к сушке и устройство для его осуществления / И.А. Шорсткий, 2019.

[11] М.И. Никитин, Е.И. Осина. Теплофизика высоких температур, 56 (4), 548 (2018).

[12] Б.Б. Балданов. Физика плазмы, 35 (7), 603 (2009).

[13] Ю.Г. Юшков. Тез. Докл. IV Междунар. Крейнделевского семинара „Плазменная эмиссионная электроника“ (УланУдэ, Россия, 2012)

[14] N. Naudé, J.P. Cambronne, N. Gherardi, F. Massines. J. Phys. D: Appl. Phys., 38 (4), 530 (2005).

DOI: $10.1088 / 0022-3727 / 38 / 4 / 004$

[15] Yangyang Fu, Peng Zhang, John P. Verboncoeur. Appl. Phys. Lett., 112, 254102 (2018). DOI: 10.1063/1.5037688

[16] А.С. Иванов, В.А. Ильин, В.Н. Титов. Электроника и микроэлектроника СВЧ, 2 (1), 220 (2015).

[17] Н.Л. Казанский, В.А. Колпаков, А.А. Колпаков, С.В. Кричевский, В.В. Подлипнов. Научное приборостроение, 22|,(1), 13 (2012).

[18] К.М. Скупов, И.И. Пономарев, Д.Ю. Разоренов, В.Г. Жигалина, О.М. Жигалина, Ю.А. Волкова, Ю.М. Вольфкович, В.Е. Сосенкин. Электрохимия, 53 (7), 820 (2017).

[19] Ю.П. Райзер. Физика газового разряда (Наука, М., 1992)

[20] У. Юсупалиев. Краткие сообщения по физике Физического института им. П.Н. Лебедева РАН, 11, 45 (2007).

[21] Е. Куффель, В. Цаенгль, Д. Куффель. Техника и электрофизика высоких напряжений (Интеллект, М., 2011)

[22] И.А. Шорсткий, N. Yakovlev. Перспективные материалы, 3, 70 (2021).

[23] Л.А. Арцимович, Р.З. Сагдеев. Физика плазмы для фбизиков (Атомиздат, М., 1979) 